reasonable amount of snow has been gathered in them. A distribution model has been applied to these conceptual snow dams, which takes into account both topographical and meteorological distributions, as well as that of solar radiation within the basin. The model combines a calculation of net heat influx into the snow surface (Koike and others, 1985) with a calculation of direct and indirect runoff components ( $\mathrm{Lu}$ and others, 1989), routing the former down the meshed channel network and the latter with the lumped model.

A snowmelt calculation started on 3 April 3 1990, demonstrates that the conceptual snow dams increase summer stream flow well into August.

\section{REFERENCES}

Koike, T., Y. Takahasi and S. Yosino. 1985. A study on modeling of snowmelt distribution. Proc. Jpn Soc. Civ. Eng., 363, 165-174.

Lu, M., T. Koike and N. Hayakawa. 1989. Distributed rainfall-runoff model using radar rain gauge. In Proceedings of the 33rd Japanese Conference on Hydraulics. Tokyo, Japan Society of Civil Engineers, 91-96.

The accuracy of references in the text and in this list is the responsibility of the authors, to whom queries should be addressed.

\title{
Use of Gaz.ex for Japan's central mountains
}

\author{
ISAO KAMIISHI, \\ ARGOS Co. Ltd., Gakkouchou Arai, Japan \\ AKIMICHI IIYOSHI, \\ Tokyo Club Inc., Sanbongishinden Arai, Japan \\ Norio Hayakawa, \\ Nagaoka University of Technology, Nagaoka, Niigata 940-21, Japan \\ KUNIO KAWADA \\ Toyama University, Toyama 930, Japan
}

\section{SUMMARY}

Japan's central mountains receive a large quantity of snow, due to winter winds blowing across the Sea of Japan. This snow is generally heavy and very wet. In this region, development of large-scale ski areas is increasingly common in recent years, making development of avalanche control an urgently needed technology.

Gaz.ex, an avalanche-blasting device recently developed in France, appears a promising technology for this environment, although it has been used mainly in the area where snow is light and the weather quite cold. Gaz.exes of different capacity have been installed and tested on Mount Ougenashi, Niigata Prefecture of Japan.

The eastern slope of Mount Ougenashi (elevation $1429 \mathrm{~m}$ ) is being developed as a ski area. On this slope, two Gaz.exes were installed in December 1991 at an elevation of about $1200 \mathrm{~m}$. Numbered A-1 and A-2, their capacities are, respectively, $3.0 \mathrm{~m}^{3}$ and $2.6 \mathrm{~m}^{3}$. In normal years the maximum snow depth reaches almost $7 \mathrm{~m}$ at this location. Deposited snow quickly turns to compacted or granular snow, with density of $0.3-0.4 \mathrm{~g} \mathrm{~cm}^{-3}$. Minimum temperatures are $-10^{\circ} \mathrm{C}$ at this location.

More than a dozen test firings of these Gaz.exes in January and February 1992 failed to set off avalanches. Most were done under clear skies and in daytime, when snow surfaces became hard-crusted.

Success was obtained on 27 February 1992, when at
A-1 an avalanche was released with width of $100 \mathrm{~m}$, flowing down to the valley bottom and then uphill over the other side of the valley to come to a stop $600 \mathrm{~m}$ from

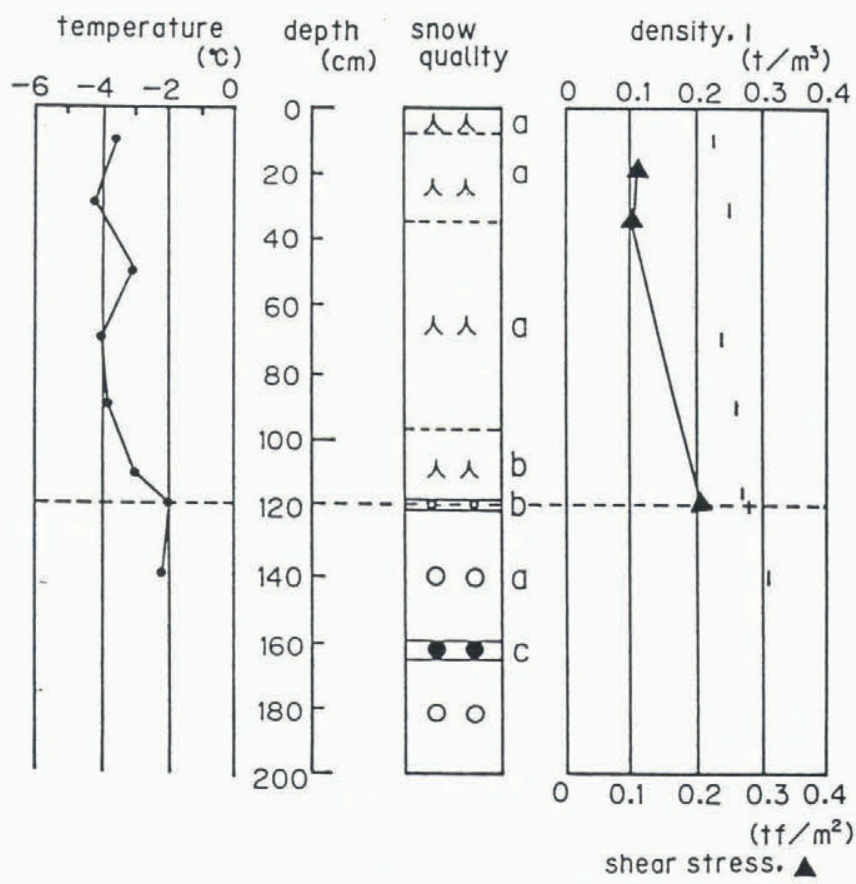

Fig.1. Snow-pit observation at $A-1$. 
the release point. A much narrower avalanche set off by A-2 traveled about $300 \mathrm{~m}$.

A snow-pit observation at the release point of $\mathrm{A}-1$ is given in Figure 1, showing a surface layer of $120 \mathrm{~cm}$ thickness lying over the bottom layer, with a fragile layer of solid-type depth hoar between. A shear test showed that the snow layer was at the brink of fracture, confirming that the avalanche was released at this fragile layer.

Snow depth temperature and weather conditions prior to the experiment favoured the formation of this fragile layer.

\title{
Experiments on a snow-melting system using circulating low-temperature fluid
}

\author{
Katsunori Nagano, KiYoshi OchifuJi AND MaKoto NAKamura \\ Faculty of Engineering, Hokkaido University, Sapporo 060, Japan
}

\section{SUMMARY}

The feasibility of a snow-melting system using lowtemperature fluid circulation was examined experimentally.

First, the relationship between pipe embedded depth (d) and pipe pitch (p) were examined by using the steady-state line-source theory. Unevenness of heat flux emitted from the slab surface is approximately $10 \%$ at $\mathrm{d} / \mathrm{p}$ of 0.48 and $20 \%$ at $\mathrm{d} / \mathrm{p}$ of 0.38 . The results of analysis of dimensionless heat flow from pipe surface and dimensionless pipe surface temperature showed that recommended $\mathrm{d} / \mathrm{p}$ is between 0.35 and 0.43 in the case of $1.27 \mathrm{~cm}$ pipes and $150 \mathrm{~mm}$ pitch.

Two experimental slabs for snow melting were constructed on the campus of Hokkaido University in Sapporo. Slab A featured concrete for the surface layer and the pipe-embedded layer, while slab B had asphalt for the surface layer over sand and cement in the embedded layer. Both utilized hot-fluid systems. $1.27 \mathrm{~cm}$ plastic pipes were embedded in the slab at a depth of $60 \mathrm{~mm}$ as dictated by the results of our theoretical analysis. Pipe pitch was $150 \mathrm{~mm}$ and the ratio of depth to pitch $(\mathrm{d} / \mathrm{p})$ was 0.6 .

The continuous experiment, in which low-temperature fluid at either $15^{\circ} \mathrm{C}$ or $10^{\circ} \mathrm{C}$ was circulated continuously, was conducted 27 December 1991-17 January 1992. Figure 1 shows the percentages of time during the total experiment in which surface temperature was maintained above $0^{\circ} \mathrm{C}$. With fluid constantly circulated at $15^{\circ}$ or $10^{\circ} \mathrm{C}$, these values were about $98 \%$ and $85 \%$, respectively, in the case of slab $\mathrm{A}$, and about $70 \%$ and $62 \%$, respectively, in the case of slab B.

\begin{tabular}{|c|c|c|c|c|c|}
\hline \multirow{2}{*}{$\begin{array}{l}\text { fluid } \\
\text { temp }\end{array}$} & \multicolumn{2}{|c|}{ Slab-A } & \multicolumn{2}{|c|}{ Slab-B } & \multirow{2}{*}{$\begin{array}{c}\text { upper } \\
\text { center }\end{array}$} \\
\hline & upper & center & upper & center & \\
\hline $15^{\circ} \mathrm{C}$ & $97.7 \%$ & $94.1 \%$ & $70.2 \%$ & $68.6 \%$ & Q \\
\hline $10^{\circ} \mathrm{C}$ & $85.2 \%$ & $81.8 \%$ & $61.6 \%$ & $58.8 \%$ & pipe \\
\hline
\end{tabular}

Fig. 1. Percentages of the time the surface temperature was maintained above $0^{\circ} \mathrm{C}$.

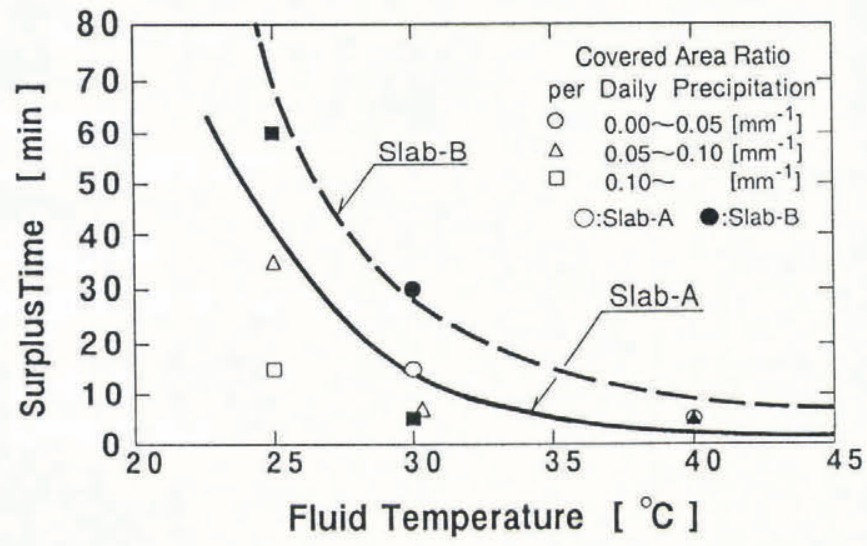

Fig. 2. The relationship between the circulated-fluid temperature and required surplus time satisfied the coveredarea ratio per daily precipitation under 0.05 .

Therefore, a snow-melting system based on continuous circulation of low-temperature fluid is feasible in the city of Sapporo.

The intermittent experiment, in which fluid at $25^{\circ} \mathrm{C}$ and $40^{\circ} \mathrm{C}$ was circulated intermittently, linked with a snowfall catch sensor and a delay timer, ran 17 January23 March 1992. The snow-covered area ratio, (i.e. the ratio of snow-covered area to total slab surface area at $2100 \mathrm{~h}$ ) was introduced to estimate the performance of snow melting. These values were classified into ten stages between 0.0 and 1.0 by photographs. Figure 2 shows the relationship between circulated-fluid temperature and required surplus circulating time after snowfall had stopped when the covered-area ratio per daily amount of precipitation was $<0.05$. In the case of concrete slabs, a long surplus time is required to satisfy this condition where fluid temperature is $<30^{\circ} \mathrm{C}$. However, if fluid temperature is $>35^{\circ} \mathrm{C}$, no surplus time is required. Therefore, $30^{\circ} \mathrm{C}$ is the minimum circulated-fluid temperature to melt snow with a relatively high efficiency and short surplus time. However, a fluid-temperature increase of $5^{\circ} \mathrm{C}$ is required in the case of asphalt slabs. 